\title{
Review Article \\ The Development of SONAR as a Tool in Marine Biological Research in the Twentieth Century
}

\author{
John A. Fornshell ${ }^{1}$ and Alessandra Tesei $^{2}$ \\ ${ }^{1}$ National Museum of Natural History, Department of Invertebrate Zoology, Smithsonian Institution, Washington, DC, USA \\ ${ }^{2}$ AGUAtech, Via delle Pianazze 74, 19136 La Spezia, Italy
}

Correspondence should be addressed to John A. Fornshell; johnfornshell@hotmail.com

Received 3 June 2013; Revised 16 September 2013; Accepted 25 September 2013

Academic Editor: Emilio Fernández

Copyright (C) 2013 J. A. Fornshell and A. Tesei. This is an open access article distributed under the Creative Commons Attribution License, which permits unrestricted use, distribution, and reproduction in any medium, provided the original work is properly cited.

\begin{abstract}
The development of acoustic methods for measuring depths and ranges in the ocean environment began in the second decade of the twentieth century. The two world wars and the "Cold War" produced three eras of rapid technological development in the field of acoustic oceanography. By the mid-1920s, researchers had identified echoes from fish, Gadus morhua, in the traces from their echo sounders. The first tank experiments establishing the basics for detection of fish were performed in 1928. Through the 1930s, the use of SONAR as a means of locating schools of fish was developed. The end of World War II was quickly followed by the advent of using SONAR to track and hunt whales in the Southern Ocean and the marketing of commercial fish finding SONARs for use by commercial fisherman. The "deep scattering layer" composed of invertebrates and fish was discovered in the late 1940s on the echo sounder records. SONARs employing high frequencies, broadband, split beam, and multiple frequencies were developed as methods for the detection, quantification and identification of fish and invertebrates. The study of fish behavior has seen some use of passive acoustic techniques. Advancements in computer technology have been important throughout the last four decades of the twentieth century.
\end{abstract}

\section{Introduction}

During the twentieth century, the use of acoustics to study life in the oceans was developed into a significant tool for research in marine biology. The purpose of this paper is to briefly recount the process by which the use of acoustics as a biological research tool took place. The general pattern was the development of acoustic technology for nonbiological research uses, navigation and military operations to name two and then the application of that technology to the detection and study of marine life. By the end of the twentieth century, acoustic technology had become a significant factor in marine biological research. Marine biologists were developing acoustic equipment for the specific purpose of studying life in the oceans.

The development of modern acoustic technologies for use in the ocean environment began during the second decade of the twentieth century. The First World War provided a significant stimulus for the advancement of ocean acoustics research. Following the war, active acoustic ranging devices in the form of echo sounders began to be employed in measuring ocean depths. Soon, acousticians began to recognize the ability to detect marine organisms, principally fish, using these devices. The use of sound to detect fish as a tool in the fishing industry and fisheries research began a slow development from the mid-1920s until the out-break of the Second World War. This conflict produced an even larger stimulus for the development of knowledge about the behavior of sound in the marine environment. Following the Second World War, the development of SONAR as a tool in biological research accelerated constantly. The "Cold War" also led to the development of advanced knowledge of ocean acoustics and sophisticated passive SONAR technology which became available following the collapse of the Soviet Union in 1991. In this brief history, the developments are chronicled in terms of the first uses of acoustics for biological work prior to World War II; subsequent to this conflict, for the period from 1946 to 2000, marine mammal research, 
plankton biology research, and fisheries biology are each treated as a separate thread in the development of SONAR as a tool in biological research.

\section{Early Developments}

Many historians site the sinking of the RMS Titanic as the immediate stimulus for the development of underwater acoustic ranging technology. In response to this event, Reginald Fessenden developed the "Fessenden oscillator" to detect icebergs and the sea floor. This device was first used on the US Coast Guard Cutter Miami in 1914 [1, 2]. The threat of German submarines during the First World War led to significant advances in underwater acoustic technology. The most important contributions in the development of active acoustic detection devices were made by the team of the French physicist, Paul Langevin, and the Russian Constantin Chilowsky. These workers produced an acoustic transmitter which could be mounted on a ship. Their initial instrument emitted sounds at a frequency of $38 \mathrm{kHz}$ (see [1] for a complete summary of the principles of underwater acoustics). By the year 1919, a device working in the frequency range from $20 \mathrm{kHz}$ to $50 \mathrm{kHz}$ was being installed on warships. R. W. Boyle coined the acronym ASDIC (Anti-Submarine Detection Investigation Committee) for use in reference to underwater acoustic detection devices [1-3]. In 1922, Harvey Hayes working on the USS Stewart, a navy destroyer, introduced the use of the echo sounder to measure water depths; he ran a transect across the Atlantic Ocean from Newport, Rhode Island to Gibraltar, making a total of 900 depth measurements. Between 1923 and 1928, US Coast and Geodetic Survey vessels were fitted with deepwater sounding instruments. Similar equipment was being fitted on survey ships of the Royal Navy Hydrographic Office and the German Navy's research ship Meteor. This marks the beginning of the use of acoustics in an organized fashion to study the marine environment [4].

Portier reported on the possibility of detecting sardines using an echo sounder [5]. In 1927, Rallier du Baty was the first to attribute false echoes on echogram recordings from the Grand Banks in the western North Atlantic as being indications of the presence of cod, Gadus morhua [6]. Two years later, in 1929, Kimura published the results of experiments in which he demonstrated that fish could be detected with the relatively simple acoustic equipment of his time [7]. In 1935, Edgell using an echo sounder on the Royal Navy Hydrographic Office survey vessel HMS Challenger was able to detect fish in the North Atlantic [8]. In the mid-1930s, the use of echo sounders by fishing vessels began on a very limited scale [9]. Norwegian fisheries biologists used echo sounders to survey cod populations in Vestfjord and, by 1937, included acoustic surveys of herring [10-12]. Balls, who was captain of the herring drifter Violet and Rose, used the echo sounder on his vessel to improve the efficiency of his fishing effort $[13,14]$.

The use and development of acoustic methods for fisheries science were interrupted by the Second World War. The period from 1939 to 1945 , World War II, saw an extremely rapid development of our understanding of the physics of sound propagation in the sea. The acronym, SONAR (SOund Navigation And Ranging), was proposed by F. V. (Ted) Hunt of Harvard University in 1942 and is the term most commonly applied to acoustic detection devices, both active and passive $[1,15]$. This new found knowledge was quickly applied to more peaceful enterprises, the commercial whaling and fishing industries in particular.

\section{SONAR Applications in the Study of Marine Mammals}

Following the end of World War II, 1946, surplus military SONAR units were fitted onto some whale catcher vessels of European nations and were used to hunt whales in the Southern Ocean. The use of this equipment greatly improved the efficiency of the whaler's efforts in killing whales. The first commercial acoustic detection equipment for the hunting of whales was being manufactured and marketed by the Kelvin-Hughes Company in 1948. The use of SONAR to actively track a whale with the technology available in the late 1940s was limited to ranges of about 1 mile, $1600 \mathrm{~m}$, with an optimal range from $450 \mathrm{~m}$ to $900 \mathrm{~m}$. By 1956, more than forty catcher boats from Norway, Great Britain, and Denmark were equipped with the Kelvin-Hughes Echowhale Finder. The installation of SONAR equipment on pelagic Japanese whale catcher vessels began in 1958 and was universal by 1962 . The installation of acoustic detection equipment in Japanese coastal whale catcher vessels began earlier, in 1950, but was never in use on all members of the coastal whaling fleet [16].

In the case of baleen whales, the SONAR pings frightened the whales resulting in an escape behavior in which the animals swam at high speed near the surface in a straight line away from the sound source. This caused them to tire more quickly and made it easier to follow the whale and kill it. In hunting sperm whales, which tend to dive to great depths when being pursued, the SONAR was used to track the animal during its dive and to position the catcher vessels near the place where the whale surfaces. Sperm whales have been observed to modify their click frequency to match that of a tracking SONAR [16].

In 1963, Walker, using passive listening equipment, reported on the detection of underwater sounds with widespread geographic distribution, apparently of biological origin. The low-frequency, $20 \mathrm{~Hz}$, sounds were detected in the North Atlantic and North Pacific Oceans. The trains of pulses with a period of approximately ten seconds were observed to (a) be point sources, (b) to move with a speed of five knots or less, and (c) to be somewhat intermittent, that is, to be punctuated by periods of silence. The conclusion that Walker reached was that they approximated the sounds of a large mammal's heartbeat. They would have been less audible while the whale was on the surface and large marine mammals have depressed heart rates when diving [17].

During the "Cold War," 1948 to 1990, the reliance on passive acoustic methods to detect and track submarines gained favor and resulted in the expenditure of $\$ 15$ billions over 40 years by the American defense establishment to develop and deploy the SOund SUrveillance System (SOSUS). During World War II, it had been discovered that, at the depth in 
the ocean where sound velocity is minimum, sound energy becomes trapped and travels for great distance. This "sound channel" or SOFAR level would allow a listener to hear sounds from great distances, tens of thousands of kilometers. In the 1950s, the US Navy began building the SUSOS in the "sound channel". The system consisted of a number of large hydrophone arrays mounted on the sea floor at the depth of minimum sound velocity, the SOFAR level. By linking these arrays into a network of listening stations, Soviet submarines could be located and tracked even if they were thousands of miles away [18].

During the 1980s, Surface Towed Array Sonar System (SURTASS) was developed to complement the fixed hydrophone arrays. This was a long string, up to $5000 \mathrm{~m}$, of acoustic transducers towed behind an ocean surveillance ship, thus allowing American and NATO navies to track Soviet submarines from the time they entered the North Sea without actively emitting sounds, which would have told the submariners that they were being tracked. The basic research, which facilitated this purely operational military project, would ultimately lead to a number of research tools for biological, physical, and geological oceanographic research [18].

In 1991, the navy largely decommissioned the SOSUS but left a small number of monitoring posts, three in the North Pacific Ocean, operational and made these available to the scientific community. Different marine mammals produce vocalizations, which are characteristic of each species, allowing them to be tracked and identified at significant distances. An individual blue whale was tracked for 43 days using the SOSUS network [19]. The decommissioned SOSUS listening posts allowed cetacean biologist to track migrating whales in the North Pacific Ocean, blue whales, Balaenoptera musculus, and fin whales, Balaenoptera physalus, observed using the seafloor array in the Northeast Pacific [20, 21].

The blue whale call sequences that were identified were long series of repetitive down swept tonal calls with fundamental frequencies usually below $20 \mathrm{~Hz}$ and several harmonics, repeated variably from 3- to 10 -minute intervals, often over several hours. Blue whale sequences often were received over distances of $500 \mathrm{~km}$ or more [22].

Moore led a team of researchers using the largely decommissioned SOSUS facility in the North Pacific and established the source of the $20 \mathrm{~Hz}$ sounds first observed by Walker in 1963 as the calls of fin whales [23].

The fin whale call sequences that were identified were the repetitive down swept $20 \mathrm{~Hz}$ pulse series with the most energy at and a little above $20 \mathrm{~Hz}$ and little harmonic energy. Pulses were repeated regularly at rates of a few seconds in characteristic temporal patterns with three to four rests of a few minutes each hour over periods of 16 hours or more. These were the songs associated with male reproductive displays, best known from calving and breeding aggregations near shore [24].

Similar work was carried out in the Northeastern Atlantic Ocean on humpback whales, Megaptera novaeangliae, when Charif et al. used the Integrated Underwater Sound System/SOund SUrveillance System (IUSS/SOSUS) to study the seasonality of acoustic behavior and migration behavior of humpback whales, in the Northwest Atlantic Ocean between Iceland and the United Kingdom. The IUSS/SOSUS transducer arrays are bottom-mounted allowing both direction and distance to the source to be determined. Spectrographic analysis of the recorded signals allowed the determination of the species of the source animal(s) [25].

Marine biologists were learning a great deal about the acoustic behavior of the whales using the partially decommissioned SUSOS. Humpback whale song components could be recognized reliably, although only the frequencies below a few hundred Hertz were typically received. These were the songs associated with male reproductive displays, best known from calving and breeding aggregations near shore. Although blue, fin, and humpback whales have variable but generally similar source levels and frequencies in these calls, blue whale calls often appeared to be received over longer distances. This suggests that these calls were more consistently produced at depths that allowed better transmission via deep sound channels to the bottom mounted hydrophones arrays. If the fin and humpback whales were mating display calls, then they would have been near the surface and in shallow water [2025].

During the "Cold War," 1948 to 1990, there was a steady decrease in the operating frequencies and an increase in the amplitude/energy being radiated by operational active SONARs culminating in the AN/SQS 53A-C (A-army, Nnavy, S-Sonar, Q-surface ship, and S-search), which operated from 2.6 to $3.5 \mathrm{kHz}$ with a power output of $235 \mathrm{~dB}$ referenced to $1 \mu \mathrm{Pa}$ at $1 \mathrm{~m}$. These antisubmarine optimized SONARs had little biological applicability, although they may have significant impact upon marine mammals due to the high power levels $[2,26]$. In the mid-1990s, NATO Centre for Maritime Research and Experimentation (CMRE, called SACLANTCEN at that time and NURC more recently) started a research programme devoted to understanding the relationship between sound in the ocean and marine mammal behaviour. A series of whale strandings in the 1990 s and early 2000s highlighted the need to understand this relationship. Although navies throughout the world use sonar during tests and training exercises, little was known about the relationship between active sonar and marine mammal strandings. The concern for environmental safety led researchers at NURC to establish the SOLMAR (Sound, Ocean and Living Marine Resources) project, later renamed Marine Mammals Risk Mitigation Project (MMRM), to investigate the phenomenon and attempt to find methods of mitigating harm to whales in the sea when the loud low-frequency active SONARs are in use. This work, which combined the use of tagging studies and visual sightings from aircraft and ships with the use of passive acoustic methods for detecting whales and making observations over very wide frequency range, led to new knowledge about whale [2730]. The vocalizations of Cuvier's beaked whale, for instance, were found to have the most energy between 20 and $60 \mathrm{kHz}$ $[31,32]$. The research conducted as part of the MMRM Project involved developing new technologies which among others included towed arrays of passive transducers to detect whales. These towed passive acoustic arrays worked on the same principles as the SURTASS described above. Such equipment 
allowed acousticians to assess the risk to marine mammals in a study area. It also led to the observation that some whales, sperm whales, Physeter macrocephalus, may be present in the same waters as Cuvier's beaked whales, Ziphius cavirostris, and not be affected by the high intensity sounds [27, 28, 31].

Acoustics have also been used in an effort to interpret some peculiar behavior of marine animals; a valuable example is represented by the work conducted by Leighton et al. in order to understand the reason why groups of humpback whales sometimes generate "bubble nets" in the form of a cylindrical curtain of shallow bubble cylinders to trap their prey, which they then consume by rising from beneath. It is possible that the whales emit a sound which remains trapped within the bubble net, thereby scaring the prey and preventing it from escaping [33].

\section{SONAR Applications for the Study of Invertebrate Animals}

In the year 1946, depth recorders were showing the existence of a "deep scattering layer" which migrated vertically on a diurnal cycle [34]. This phenomenon proved to be myctophid fish and planktonic organisms including physonect siphonophores, euphausids, and copepods which migrated vertically as a result of diurnal variations in solar illumination [35-39]. Earlier workers had recognized acoustic signatures as having a biological origin, such as cod [6]. In the case of the deep scattering layer, the acoustic signature was observed as an ocean-wide phenomenon and subsequently identified as biological in nature. Most of the observations were made at $12 \mathrm{kHz}$ and the organisms proved to be invertebrate members of the zooplankton community. This marked the beginning of the use of acoustics to discover and study marine biological topics that were new to science. An important step forward was conducted by Stockhausen and Figoli in their 1973 study using an efficient experimental method (and the appropriate sonar system, which was very advanced for that time) for measuring volume scattering strength of the deep scattering layers, illuminated from beneath. The methodology used explosive sources and a directional receiver placed in a bistatic configuration in very deep waters, with the beam looking upward, so that the scattering layers were profiled from below. This allowed a much higher depth resolution versus frequency, especially when, during the night, the scattering layers lie very shallow [36].

The availability of higher frequency SONARs for use by marine biologists in the 1970s led to the use of acoustics for the study of invertebrates. Holliday and Pieper working on the problem of detecting and identifying smaller invertebrate animals developed the Multiple-frequency Acoustical Profiling System (MAPS) which can be used to profile the water column using the multiple-frequency methods they pioneered in the 1970s and 1980s [40]. The device can also be towed behind a moving ship. This marked the beginning of acoustic research dedicated to studying invertebrates in the pelagic environment.

In 1977, Greenlaw measured the backscattering spectra of preserved planktonic crustaceans [41]. The process of preservation changes the relative values of celerity and density by very small amounts. These changes, however, are acoustically significant causing up to a $40 \%$ variation in the target strength (TS). He also noted that the TS varied from the predicted values for $k a$ ( $k$ is the wave number, $2 \pi / \lambda$, and $a$ is the characteristic cross section length) greater than 1. It also varied significantly as the aspect of the animal changed. Elongate species such as krill and Sergested shrimp are directional reflectors, producing much larger TS when viewed dorsally or laterally as compared to frontal aspect. This work was followed five years later with a paper published by Greenlaw and Johnson presenting the values of the ratios of sound velocity in the organism to that in seawater and the ratio of the density of the animals to that of seawater for a wide variety of zooplankton species using values for fresh/living specimens in seawater. This information was of significant use for researchers studying the acoustic signatures of invertebrate animals [42]. This work was necessary if marine biologists were to be able to identify acoustically detected planktonic animals.

During the 1980s, acoustical research on micronekton followed two different pathways. (1) Holliday and Pieper developed multiple-frequency inversion methods to estimate the acoustical size distribution from volume backscattering data collected with several different frequencies of sound. It has been met with significant success in estimating the zooplankton and micronekton biomass concentration in different acoustical size classes [40]. (2) Dual beam acoustical methods, first developed in fisheries research in the 1970s, have been refined to allow the resolution and analysis of echoes from individual animals such as members of the small macrozooplankton. Using this technology, the capability of estimating the acoustical distribution of a zooplankton and micronekton assemblage was developed. When the results of such an analysis are combined with the results of an echo integration analysis of the corresponding volume backscattering data, estimates of numerical density and biomass concentration could be apportioned into different acoustical size classes [43].

Volume reverberation in the ocean is due in large part to biological causes at frequencies greater than $1 \mathrm{kHz}$. Working at Woods Hole Oceanographic Institution (WHOI), Wiebe, building on earlier work by Stanton, found that backscattering cross section increases with the volume of the animal. His work also demonstrated that live specimens are stronger acoustic targets than preserved specimens. Better approximations were obtained with cylinder models as opposed to spherical models. The actual backscattering strengths are a complex function, which can be roughly approximated by cylinder or bent cylinder models $[44,45]$.

Wiebe et al. showed that the key to using high frequency sound in the study of zooplankton and micronekton was to deploy the acoustical transducer in a manner that gets the transducer sufficiently close to the animals of interest. This is due to the fact that attenuation (measured in $\mathrm{dB} / \mathrm{m}$ ) approximately increases with the square of the frequency. In the case of the dual beam method, the range is further limited by the need to resolve individual targets. Beam angles of $3^{\circ}$ and $10^{\circ}$ and a frequency of $420 \mathrm{kHz}$ were used [45]. 
The target strength of an organism can be plotted as a function of frequency. In this case, the value of the parameter $k a$ proves to be very important; below a value of 1 , the slope of target strength in $\mathrm{dB} / \mathrm{ka}$ rises very steeply with a slope of about 80 ; above a $k a$ value of 5 , the average slope is nearly horizontal. For most living organisms, this curve is not smooth but rather characterized by undulations due to constructive and destructive interference resulting from the external and internal morphology of the target species. These undulations may be used to identify the organisms being observed.

This phenomenon was used by several workers to develop techniques for the acoustic identification of different taxa in the sea. Multiple transducers, each operating at a specific frequency are one solution to this problem. Alternately, appropriate wide band transducers may emit a continuous wideband signal with a chirp modulated over a range of frequencies greater than ten percent of the center frequency. The former method was used by Coombs and Barr in 2004 and the latter method was used by Chu and Stanton in 1998 and by Stanton et al. [46-48].

The underwater acoustic sensor BIo-Optical Multifrequency Acoustic and Physical Environmental Recorder (BIOMAPER), developed at WHOI in the mid-1990s, represented a significant advance in the use of acoustics to study marine invertebrates [49]. In its initial form, transducers operating at $120 \mathrm{kHz}$ and $420 \mathrm{kHz}$ allowed the detection of organisms with characteristic acoustic cross sections on the order of centimeters. This meant that the acoustic device was detecting herbivores, euphausids mysid shrimp, Penaeidae shrimp, primary carnivores, and small fish. Efforts to improve the system led to the use of seven different frequencies, $38 \mathrm{kHz}, 43 \mathrm{kHz}, 120 \mathrm{kHz}, 200 \mathrm{kHz}, 420 \mathrm{kHz}, 1 \mathrm{MHz}$, and $2 \mathrm{MHz}$ in BIOMAPER II. This refinement along with the ability to vary the depth of the tow fish depth greatly enhanced the capability of acoustically sampling a wider range of trophic levels including at least some of the primary producers, planktonic algae $[50,51]$.

\section{SONAR Applications for the Study of Fish}

In the period between 1948 and 2000, the use of acoustics in fisheries biology increased rapidly. At this time, 1948, the Japanese firm, Fururno Industries, began to market fish finders to the commercial fin fish industry. In Europe, the Kongsberg Simrad Corporation also marketed an increasingly sophisticated line of SONARs with vertically steerable beams, multiple beams, and multiple frequencies, specifically tailored to the needs of fishermen seeking fin fish in the North Atlantic Ocean and adjacent seas from the early 1950s. In the last quarter of the twentieth century, these companies were joined by Teledyne RESON A/S in the production of scientific SONARs.

Fishermen also make great use of the echo sounder to locate fish. In this case, the vertically oriented beam shows the fisherman the depth and bottom topography and may indicate the presence of fish. The strength of the echo from the fish may be used to infer both the quantity of fish and, in some instances, the species [52]. The echo sounder may be single beam configuration, dual beam configuration with the transducers in a circular pattern, or a split beam configuration with the transducers divided into quadrants. The dual beam configuration allows the observer to determine the angle of the targets, fish, to the axis of the beam. The split beam configuration allows the observer to determine the angular position of the target, fish, to the observer. If the echo sounder has a single beam, the target strength and range may be displayed. If the echo sounder has a dual beam configuration, the target strength and relative angle to the axis of the beam are displayed. A split beam configuration allows the display of target strength and relative position to the echo sounder [53].

As the years progressed, there was a steady shift from adapting military and navigational hardware to the needs of fisheries biology to the development of acoustic hardware and methodologies specifically for the research needs of this field. These research SONARs included multibeam SONAR, side scan SONAR, parametric SONAR, synthetic aperture SONAR, and conventional low-frequency SONAR [53-56]. These different types of SONARs may be combined to facilitate specific research interests. The combination of side scan SONAR and echo sounder gives rise to the multibeam SONAR (generally exploiting the Mills Cross arrangement of a projector and a line hydrophone array) for highresolution, three-dimensional sensing of fish populations. Using advanced computer data analysis methods, it is possible to construct a three-dimensional image of fish schools. This process allows the fisheries biologist to determine the length, width, vertical dimension, and position in the water column of a school of fish that has been detected. In some instances, this may allow the density estimation and the identification of the species of fish in the schools when sufficient knowledge of schooling behavior is available. In addition, the avoidance behavior patterns of fish may be quantitatively studied $[57,58]$.

Active acoustics/SONAR using sound energy generated by transducers to study fish populations dates from 1930s, as described earlier in this paper. The commercial application of such information was and still is a major factor in the development of active SONAR for fisheries research. The commercially available echo sounders available in the postSecond World War period were adequate for locating schools of fish and individual fish but were only marginally adequate for basic research. Acoustic devices used for research may be monostatic, when a single transducer is used to both transmit and receive sound energy or when the transmitter and receiver are colocated, or bistatic when the transmitter and receiver(s) are separated by a distance large enough to be comparable to the distance to the target. The former configuration is generally less complicated to carry out in terms of both cost and geometrical/mechanical issues and is used more often. When studying demersal fish, the transducer is mounted on the hull pointing downward, and when studying pelagic fish, it is mounted so as to transmit its beam horizontally. In both cases, the transducers consist of single or multiple piezoelectric elements which convert electrical energy into acoustic energy and/or vice versa. If one limits the description to directive sources, which are the most commonly used in this field, the emitted "ping" spreads in a conical fashion similar to that of a flashlight beam, where 
objects near the axis of the beam appear brighter than those off the axis. Similarly, objects near the axis of the acoustic beam are found to have greater acoustic amplitude than those off the axis. The edge of the main radiation beam (or lobe) is defined as the distance between the axes and where the echo intensity is reduced to one-half, and twice this distances is the beam width. Also, the receiving beam is defined in the same way [59-61].

Two basic measurements are derived from acoustic data: backscatter from an individual target of interest, namely, target strength, and reverberation, which can be defined as the persistent sound scattered and reflected after emission by all the elements of target's environment [62]. When organisms are dispersed, it is possible to obtain echoes from individuals, depending on the spatial resolution of the sonar compared to the animals' size. Trout et al. first used this method to obtain the numeric density, number of organisms per cubic meter. Most of the time, fish will form schools, making echo counting impossible [63]. Medwin and Clay measured the acoustic backscattering cross section $\left(\mathrm{bs} / \mathrm{m}^{2}\right)$ and target strength (TS $=20 \log _{10}$ relative acoustic pressure) [62]. In this case, echo integration may be used in which the volume backscattering $/ \mathrm{m}^{2}$ is multiplied by the total volume being sampled [64]. This summation was shown to be linearly proportional to the population density by Foote in 1983 [65].

The application of advanced signal processing methods and the enhanced understanding of the principles of sound propagation in the sea have increased the quality and quantity of information obtained using acoustic methods. Interesting results of high-resolution population density imaging were obtained through ultrasonic echo sounders; another valuable result was obtained by applying several independent acoustic systems aimed to measure the low-frequency target strength and population density of the Atlantic herring: the lowfrequency falloff in the response of schools of hundreds of millions of animals was confirmed by the response of an individual and interpreted as being caused by the subresonance scattering of the fish swim bladder [66, 67]. The largest sources of error in fisheries acoustic surveys are incomplete coverage of the entire population, inaccuracy in proportioning backscatter to taxa, and error in estimating target strengths of individual organism [54].

Fisheries biologists using acoustics as a method of determining the size of fish stocks developed empirical models (empirical models are statistical relationships between observed and measured variables). In fisheries acoustics, the most common relationship, target strength to length regression, is used to convert echo amplitude to fish lengths. Other common relationships are volume backscatter to abundance or biomass regressions [62]. The abundance of cod, for example, could be determined by visually inspecting the sum of signals as a function of the distance steamed. The next step was automation of the process [68]. In parallel with these developments, work by Cushing showed that the target strength was greatly influenced by the presence and the size of the swim bladder [60]. This work was important in that it began the process of differentiating between different species based on the target strength [66].
In the 1970s, the accuracy of acoustic observations was greatly enhanced by the introduction of readily available inexpensive digital electronics. "Computers and modern electronics have greatly increased our ability to collect, analyze, and display acoustical data. The fundamental measurement remains a time series of voltage and the grand challenge is interpreting and translating these signals into information useful for scientists and managers [60]." Measurements were made more accurate because digital devices did not tend to drift as much as analog measurement equipment. Also, the introduction of small shipboard computers greatly speeded data processing [69]. The dependence of abundance estimates on backscatter is significant. An error of only three $\mathrm{dB}$ in target strength will result in a factor of two differences in abundance estimates [61]. The reflected sound from the swim bladder has been found to account for $90 \%$ of the total energy backscattered by a fish depending on the frequency being used [70-74].

Developing a viable means of using acoustic data to identify different taxa was recognized as one of the great challenges to the use of SONAR in fisheries biology and marine biology research [48]. Members of the zooplankton do not have a swim bladder and can be differentiated from fish which do have a swim bladder by using multiple frequencies, $12 \mathrm{kHz}$, $18 \mathrm{kHz}$, and $38 \mathrm{kHz}$ are particularly useful for identifying macroscopic fish, whereas $120 \mathrm{kHz}$ and $200 \mathrm{kHz}$ are useful for zooplankters such as krill and shrimp $[75,76]$.

Passive SONAR using acoustic energy produced by the fish themselves has also been developed as a significant research tool [59]. Passive acoustics takes advantage of sounds produced by fishes to eavesdrop on their behavior. Most fish sounds are associated with aggression, courtship, and spawning [61]. The US Navy sponsored a large scale study of the fish sounds after World War II resulting in the cataloging of the sounds made by many different species of fish [77]. Their work showed that a great number of fishes produced species-specific sounds. The types of SONAR used in research in fisheries research include single hydrophones, paired hydrophones, three, four, and five hydrophone arrays, sonobuoys, and towed arrays. The quantitative analysis of sounds produced by fish and other marine animals is typically by plotting signals in the time domain as oscillograms (amplitude versus time) and in the frequency domain (frequency versus time) as power spectra. Qualitative analysis is focused on characterizing biological sounds using terms such as chirps, whistles, and growls to name a few. By analyzing arrival times, phase shifts, from multiple hydrophones, the direction to the organisms can be determined from interferometry.

While active SONAR has been widely adopted in the post-Second World War era for estimating fish abundance, passive acoustics has not seen widespread adoption. There are three reasons for this: (1) the technology, both hardware and software, has not been commercially available; (2) the general lack of ground-truthing data necessary to make quantitative assessments based on the acoustic data; (3) the sounds that fish produce are often masked by the ambient noise in the sea [1]. 


\section{Conclusions}

The use of acoustics as a tool for biological oceanography research in the twentieth century followed the initial development of the technology for military, hydrographic, and navigational purposes. The first uses were in the field of fisheries biology where such technology offered the potential for making the process of fishing more effective and therefore more profitable. It also offered an alternative method for assessing fish stocks and hence helping fisheries managers to better husband the natural resource. The study of anthropogenic effects, wind farms, ship traffic, and military activity on marine mammals and fish is an increasingly important field of bioacoustic research. This is leading to an increased understanding of the role of acoustics in marine life as well as the effects of acoustic pollution in an ever increasingly noisy ocean. The rapid developments during the two world wars and the Cold War provided significant advances in the capabilities of acoustic detection devices. By the last quarter of the twentieth century, acoustic technology had become a significant tool in the study of marine life comparable in significance to molecular biology techniques and other leading-edge research technologies. Bioacoustics is no longer a secondary research field rather an area of research in which equipment designed specifically for acoustics research is being produced for the study of marine life. The developments of the twentieth century laid the foundations for a growing and productive research field which, in the first decades of the twenty-first century, is truly coming into its own. Bioacoustics, by the end of the twentieth century, had become a mature independent discipline, thus setting the stage for significant new advances in this area of research in the twenty-first century.

The rate of advancement of acoustic technology for the study of marine life in the twenty-first century has accelerated along with other scientific disciplines. Biologists are developing acoustic instrumentation specifically for studying marine life at many research centers around the world, which did not exist at the beginning of the twentieth century. The Woods Hole Oceanographic Institution (WHOI), the NATO CMRE, formerly (NURC), the University of Rhode Island, Florida Atlantic University, Scripps Institute of Oceanography of the University of California, the Alfred Wegener Institute, the Institute of Sound and Vibration and Research, University of Southampton, the University of Hawaii, the University of Padua's Centro Interdisciplinare di Bioacustica e Ricerche Ambientali (CIBRA), the Canadian Department of Fisheries and Oceans, and Moscow University's Nikolai Pertsov White Sea Biological Station are among the leading research centers. The work done at these institutions is being reported in several journals dedicated to acoustic research, some of which are focused directly on biological topics. It is not possible to predict where this new branch of research will take us. No one would have predicted the deep scattering layer discovered in the late 1940s. New methodologies are being produced at an ever accelerating rate facilitating the use of acoustics in the study of life in the ocean [53]. It is best to go forward with anticipation of the revelation of new knowledge and a better understanding of our existing factual information base.

\section{References}

[1] R. J. Urick, Principles of Underwater Sound, Peninsula Publishing, Los Altos Hills, Calif, USA, 3rd edition, 1983.

[2] A. D'Amico and R. Pittenger, "A brief history of active sonar," Aquatic Mammals, vol. 35, no. 4, pp. 426-434, 2009.

[3] E. Klein, "Underwater sound and naval acoustical research and applications before 1939," Journal of the Acoustic, vol. 43, no. 3, pp. 931-947, 1968.

[4] S. B. Nelson, Oceanographic Ships Fore and Aft, U. S. Government Printing Office, Washington, DC, USA, 1971.

[5] P. Portier, Sur lapplication des on des Ultra-Sonores Aux Recherches D’Océanographie Biologique, vol. 91, C. R. Société Biologique, Paris, France, 1924.

[6] R. Rallier du Baty, "La pêche sur le banc de Terre-Neuve et autour del îles," in Saint-Pierre et Miquelon Office Scientifique et Technique des Pêches Maritimes Mémoires, vol. 7, 1927.

[7] K. Kimura, "On the detection of fish-groups by an acoustic method," Journal of the Imperial Fish Institute, vol. 24, pp. 4145, 1929.

[8] J. A. Edgell, "False echoes in deep water," Hydrographic Review, vol. 12, pp. 19-20, 1935.

[9] H. Wood and B. B. Parrish, "Echo-sounding experiments on fishing gear in action," Journal du Conseil International Pour l'Exploration de la Mer, vol. 17, pp. 25-36, 1950.

[10] O. Sund, "Echo sounding in fishery research," Nature, vol. 135, no. 3423 , p. 953, 1935.

[11] S. Runnstrom, "A review of the Norwegian herring investigations in recent years," JournaL du Conseil International Pour l' Exploration de la Mer, vol. 12, pp. 123-1143, 1937.

[12] S. Runnstrom, "Quantitative investigations on herring spawning and its yearly fluctuations at the west coast of Norway," Report on Norwegian Fishery and Marine Investigations, vol. 6, p. 71, 1941.

[13] R. Balls, Fish on the Spot Line, Marconi International Marine Communications, London, UK, 1946.

[14] R. Balls, "Herring fishing with the echometer," ConseiL InternationaL Pour L'Exploration De La Mer, vol. 15, pp. 193-206, 1948.

[15] X. Lurton, An Introduction to Underwater Acoustics, Praxis Publishing, Chichester, UK, 2002.

[16] R. L. Brownell Jr., D. P. Nowacek, and K. Ralls, "Hunting cetaceans with sound: a worldwide review," Journal of Cetacean Research and Management, vol. 10, no. 1, pp. 81-88, 2008.

[17] R. A. Walker, "Some intense, low-frequency, underwater sounds of wide Geographic distribution, apparently of biological origin," Journal of the Acoustical Society of America, vol. 35, no. 11, pp. 1816-1824, 1963.

[18] L. P. Solomon, Transparent Oceans: the Defeat of the Soviet Submarine Force, Pearl River Publishing, 2003.

[19] G. J. Gagnon and C. W. Clark, "The use of U.S. Navy IUSS passive sonar to monitor the movement of blue whales," in Proceedings of the 10th Biennial Conference on the Biology of Marine Mammals, pp. 11-15, Galveston, Tex, USA, November 1993.

[20] M. A. McDonald, J. A. Hildebrand, and S. C. Webb, "Blue and fin whales observed on a seafloor array in the Northeast Pacific," Journal of the Acoustical Society of America, vol. 98, no. 2, pp. 712-721, 1995.

[21] W. A. Watkins, M. A. Daher, G. M. Reppucci et al., "Seasonahty and distribution of whale calls in the North Pacific," Oceanography, vol. 13, no. 1, pp. 62-67, 2000. 
[22] C. W. Clark and P. J. Clapham, "Acoustic monitoring on a humpback whale (Megaptera novaeangliae) feeding ground shows continual singing into late spring," Proceedings of the Royal Society B, vol. 271, no. 1543, pp. 1051-1057, 2004.

[23] S. E. Moore, K. M. Stafford, M. E. Dahlheim et al., "Seasonal variation in reception of fin whale calls at five geographic areas in the north pacific," Marine Mammal Science, vol. 14, no. 3, pp. 617-627, 1998.

[24] R. S. Payne and S. McVay, "Songs of humpback whales," Science, vol. 173, no. 3997, pp. 585-597, 1971.

[25] R. A. Charif, P. J. Clapham, and C. W. Clark, "Acoustic detections of singing humpback whales in deep waters off the British Isles," Marine Mammal Science, vol. 17, no. 4, pp. 751-768, 2001.

[26] T. F. Duda and A. D. Pierce, "History of environmental acoustics, 1960's to 2000's," in Proceedings of the MTS/IEE Oceans, Quebec City, Canada, September 2008.

[27] M. Carron, "A Nato Saclantcen marine mammal risk mitigation programm (sound ocean and living marine resources)," in Proceedings of the European Cetacean Society's 17th Annual Conference, P. G. H. Evans and L. A. Miller, Eds., pp. 59-62, 2003.

[28] G. Pavan, C. Fossati, M. Manghi, and M. Priano, "Passive acoustic tools for the implementation of acoustic risk mitigation policies," in Proceedings of the European Cetacean Society's 17th Annual Conference, P. G. H, Evans, and L. A. Miller, Eds., 2003.

[29] W. M. X. Zimmer, "Underwater acoustics and whales in the Mediterranean Sea," Polarforschung, vol. 72, no. 2-3, pp. 115-118, 2002.

[30] P. Fortescue, S. O. Hole, R. M. Robichaud et al., "Marine mammals and active sonar: a paper prepared for the NATO Military Oceanography Group," Tech. Rep., NURC publication, 2005.

[31] W. M. X. Zimmer, M. P. Johnson, P. T. Madsen, and P. L. Tyack, "Echolocation clicks of free-ranging Cuvier's beaked whales (Ziphius cavirostris)," Journal of the Acoustical Society of America, vol. 117, no. 6, pp. 3919-3927, 2005.

[32] S. M. Wiggins, M. A. McDonald, and J. A. Hildebrand, "Beaked whale and dolphin tracking using a multichannel autonomous acoustic recorder," Journal of the Acoustical Society of America, vol. 131, no. 1, pp. 156-163, 2012.

[33] T. G. Leighton, S. D. Richards, and P. R. White, “Trapped within a 'wall of sound'. a possible mechanism for the bubble nets of humpback whales," Acoustics Bulletin, vol. 29, no. 1, pp. 24-27, 2004.

[34] R. S. Diets, "Deep scattering layer in the Pacific and Antarctic oceans," Journal of Marine Research, vol. 7, no. 3, pp. 430-442, 1948.

[35] S. A. Tont, "Deep scattering layers: patterns in the Pacific," California Cooperative Oceanic Fisheries Investigations Reports 18, 1975.

[36] J. H. Stockhausen and A. Figoli, "An upward-looking bistatic research system for measuring deep scattering layers in the ocean," SACLANTCEN Technical Report 225, 1973.

[37] E. G. Barham, "Deep scattering layer migration and composition: observations from a diving saucer," Science, vol. 151, no. 3716, pp. 1399-1403, 1966.

[38] C. J. Robinson and J. Gómez-Gutiérrez, "Daily vertical migration of dense deep scattering layers related to the shelf-break area along the northwest coast of Baja California, Mexico," Journal of Plankton Research, vol. 20, no. 9, pp. 1679-1697, 1998.
[39] J. B. Hersey and R. H. Backus, "New evidence that migrating gas bubbles, probably the swimbladders of fish, are largely responsible for scattering layers on the continental rise south of New England," Deep Sea Research, vol. 1, no. 3, pp. 190-191, 1954.

[40] D. V. Holliday and R. E. Pieper, "Volume scattering strengths and zooplankton distributions at acoustic frequencies between 0.5 and $3 \mathrm{MHz}$," Journal of the Acoustical Society of America, vol. 67, no. 1, pp. 135-146, 1980.

[41] C. F. Greenlaw, "Backscattering spectra of preserved zooplankton," Journal of the Acoustical Society of America, vol. 62, no. 1, pp. 44-52, 1977.

[42] C. F. Greenlaw and R. K. Johnson, "Physical and acoustical properties of zooplankton," Journal of the Acoustical Society of America, vol. 72, no. 6, pp. 1706-1710, 1982.

[43] C. H. Green and P. H. Wiebe, "Bioacoustical oceanography: new tools for zooplankton research in the 1990s," Oceanography, vol. 3, pp. 12-17, 1990.

[44] T. K. Stanton, P. H. Wiebe, C. D. Chu Dezhanbg et al., "On acoustic estimates of zooplankton biomass," ICES Journal of Marine Science, vol. 51, no. 4, pp. 505-512, 1994.

[45] P. H. Wiebe, C. H. Greene, T. K. Stanton, and J. Burczynski, "Sound scattering by live zooplankton and micronekton: empirical studies with a dual-beam acoustical system," Journal of the Acoustical Society of America, vol. 88, no. 5, pp. 2346-2360, 1990.

[46] R. F. Coombs and R. Barr, "Acoustic remote sensing of swimbladder orientation and species mix in the oreo population on the chatham rise," Journal of the Acoustical Society of America, vol. 115, no. 4, pp. 1516-1524, 2004.

[47] D. Chu and T. K. Stanton, "Application of pulse compression techniques to broadband acoustic scattering by live individual zooplankton," Journal of the Acoustical Society of America, vol. 104, no. 1, pp. 39-55, 1998.

[48] T. K. Stanton, D. B. Reeder, and J. M. Jech, "Inferring fish orientation from broadband-acoustic echoes," ICES Journal of Marine Science, vol. 60, no. 3, pp. 524-531, 2003.

[49] P. H. Wiebe, T. K. Stanton, M. C. Benfield, D. G. Mountain, and C. H. Greene, "High-frequency acoustic volume backscattering in the Georges bank coastal region and its interpretation using scattering models," IEEE Journal of Oceanic Engineering, vol. 22, no. 3, pp. 445-463, 1997.

[50] T. C. Torkelson, T. C. Austin, and P. H. Wiebe, "Multi-frequency acoustic assessment of fisheries and plankton resources," in Proceedings of the 135th Meeting of the Acoustical Society of America, Seattle, Wash, USA, 1998.

[51] T. C. Torkelson, T. C. Austin, and P. H. Wiebe, "Multi-frequency acoustic assessment of fisheries and plankton resources," in Proceedings of the 6th Meeting of the International Congress on Acoustics, Seattle, Wash, USA, 1998.

[52] O. A. Misund, "Underwater acoustics in marine fisheries and fisheries research," Reviews in Fish Biology and Fisheries, vol. 7, no. 1, pp. 1-34, 1997.

[53] K. G. Foote, "Acoustic methods. Brief review and prospects for advancing fisheries research," in The Future of Fisheries Science in North America, R. J. Beamish and B. J. Rothchild, Eds., Springer Science, 2009.

[54] D. N. MacLennan and D. V. Holliday, "Fisheries and plankton acoustics: past present and future," ICES Journal of Marine Science, vol. 53, pp. 513-516, 1996.

[55] D. V. Holliday, "Doppler structure in echoes from schools of pelagic fish," Journal of the Acoustical Society of America, vol. 55, no. 6, pp. 1313-1322, 1974. 
[56] D. N. MacLennan and E. J. Simmonds, Fisheries Acoustics, Chapman and Hall, London, UK, 1992.

[57] F. Gerlotto, M. Soria, and P. Fréon, "From two dimensions to three: the use of multibeam sonar for a new approach in fisheries acoustics," Canadian Journal of Fisheries and Aquatic Sciences, vol. 56, no. 1, pp. 6-12, 1999.

[58] M. Soria, P. Fréon, and F. Gerlotto, "Analysis of vessel influence on spatial behaviour of fish schools using a multi-beam sonar and consequences for biomass estimates by echo-sounder," ICES Journal of Marine Science, vol. 53, no. 2, pp. 453-458, 1996.

[59] H. E. Winn, "The biological significance of fish sounds," in Marine Bio-Acoustics, W. N. Tavolga, Ed., Pergamon Press, Oxford, UK, 1964.

[60] D. H. Cushing, The Detection of Fish, Pergamon Press, Oxford, 1973.

[61] D. A. Mann, A. D. Hawkins, and J. M. Jech, "Active and passive acoustics to locate and study fish," in Fish Bioacoustics, J. F. Webb, R. R. Fay, and A. N. Popper, Eds., Springer, 2007.

[62] H. Medwin and C. S. Clay, Fundamentals of Acoustic Oceanography, Academic Press, Boston, Mass, USA, 1998.

[63] G. C. Trout, A. J. Lee, I. D. Richardson, and F. R. H. Jones, "Recent echo sounder studies," Nature, vol. 170, no. 4315, pp. 71$72,1952$.

[64] K. A. Johannesson and R. A. Mitson, "Fisheries acoustics," FAO Fisheries Technical Paper 240, 1983.

[65] K. G. Foote, "Linearity of fisheries acoustics, with addition theorems," Journal of the Acoustical Society of America, vol. 73, no. 6, pp. 1932-1940, 1983.

[66] M. Andrews, Z. Gong, and P. Ratilal, "High resolution population density imaging of random scatterers with the matched filtered scattered field variance," Journal of the Acoustical Society of America, vol. 126, no. 3, pp. 1057-1068, 2009.

[67] Z. Gong, M. Andrews, S. Jagannathan et al., "Low-frequency target strength and abundance of shoaling Atlantic herring (Clupea harengus) in the gulf of maine during the Ocean acoustic waveguide remote sensing 2006 experiment," Journal of the Acoustical Society of America, vol. 127, no. 1, pp. 104-123, 2010.

[68] P. G. Fernandes, F. Gerlottto, D. V. Holliday, A. Nakken, and E. J. Simmonds, "Acoustic applications in fisheries science: the ICES contribution," in Proceedings of the ICES Marine Science Symposium, vol. 215, pp. 483-492, 2002.

[69] O. Nakken and K. Olsen, "Target strength measurements of fish," Rapports et Procès-Verbaux des Réunions du Conseil International Pour l'Exploration de la Mer, vol. 170, pp. 52-69, 1977.

[70] R. W. G. Haslett, "Determination of the acoustic scatter patterns and cross sections of fish models and ellipsoids," British Journal of Applied Physics, vol. 13, no. 12, article 317, pp. 611-620, 1962.

[71] R. W. G. Haslett, "Acoustic backscattering cross sections of fish at three frequencies and their representation on a universal graph," British Journal of Applied Physics, vol. 16, no. 8, article 313, pp. 1143-1150, 1965.

[72] K. G. Foote, "Importance of the swimbladder in acoustic scattering by fish: a comparison of gadoid and mackerel target strengths," Journal of the Acoustical Society of America, vol. 67, no. 6, pp. 2084-2089, 1980.

[73] K. G. Foote, "Optimizing copper spheres for precision calibration of hydroacoustic equipment," Journal of the Acoustical Society of America, vol. 71, pp. 742-747, 1983.
[74] K. G. Foote, "Underwater acoustic technology: review of some recent developments," Journal of Ocean Engineering, vol. 28, no. 1-2, pp. 1-6, 2003.

[75] D. R. McKelvey, The use of two frequencies to interpret acoustic scattering layers [M.S. thesis], University of Washington, Seattle, Wash, USA, 2000.

[76] R. J. Kloser, T. Ryan, P. Sakov, A. Williams, and J. A. Koslow, "Species identification in deep water using multiple acoustic frequencies," Canadian Journal of Fisheries and Aquatic Sciences, vol. 59, no. 6, pp. 1065-1077, 2002.

[77] M. P. Fish and W. H. Mowbray, Sounds of Western North Atlantic Fishes: A Reference File of Biological Underwater Sounds, The Johnb Hopkins University Press, Baltimore, Md, USA, 1970. 

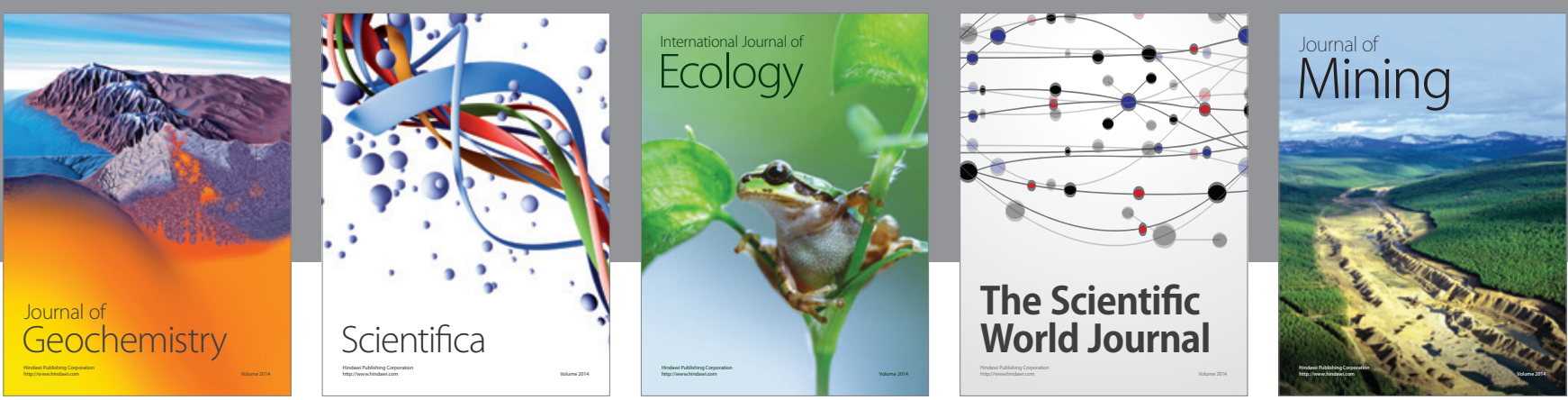

The Scientific World Journal
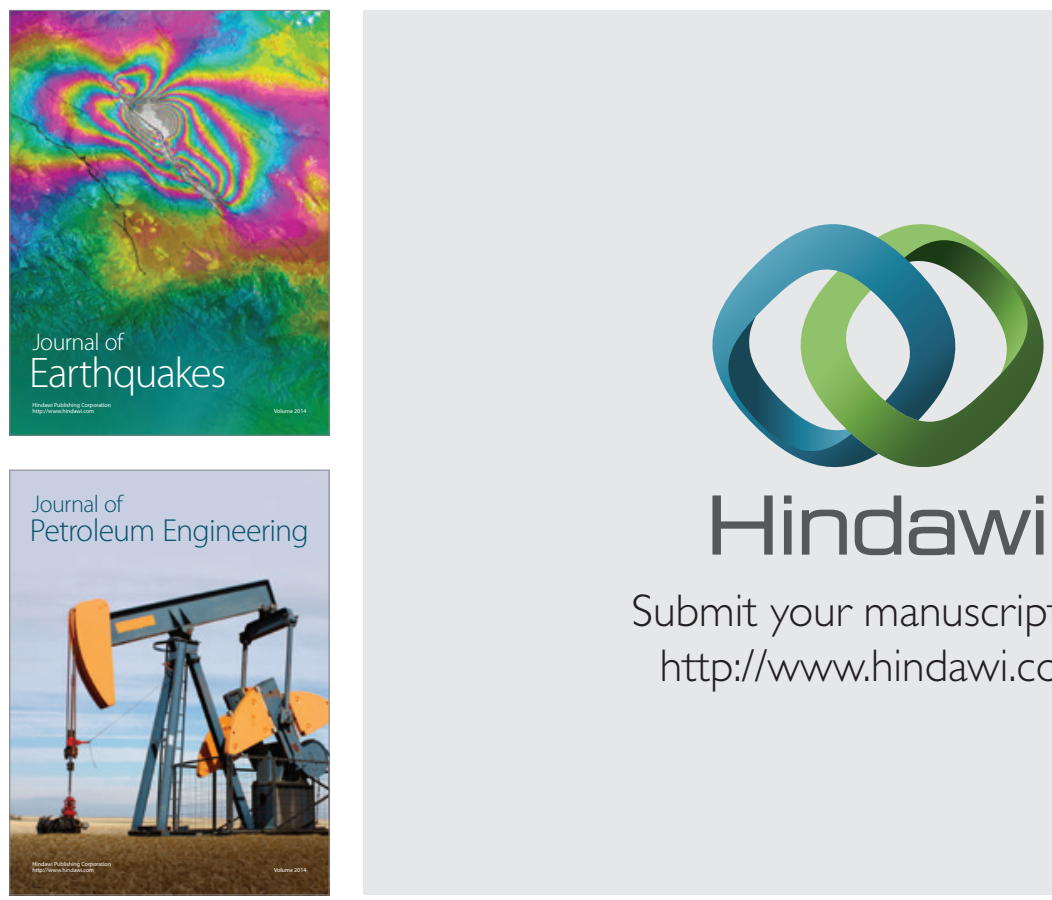

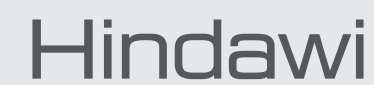

Submit your manuscripts at

http://www.hindawi.com
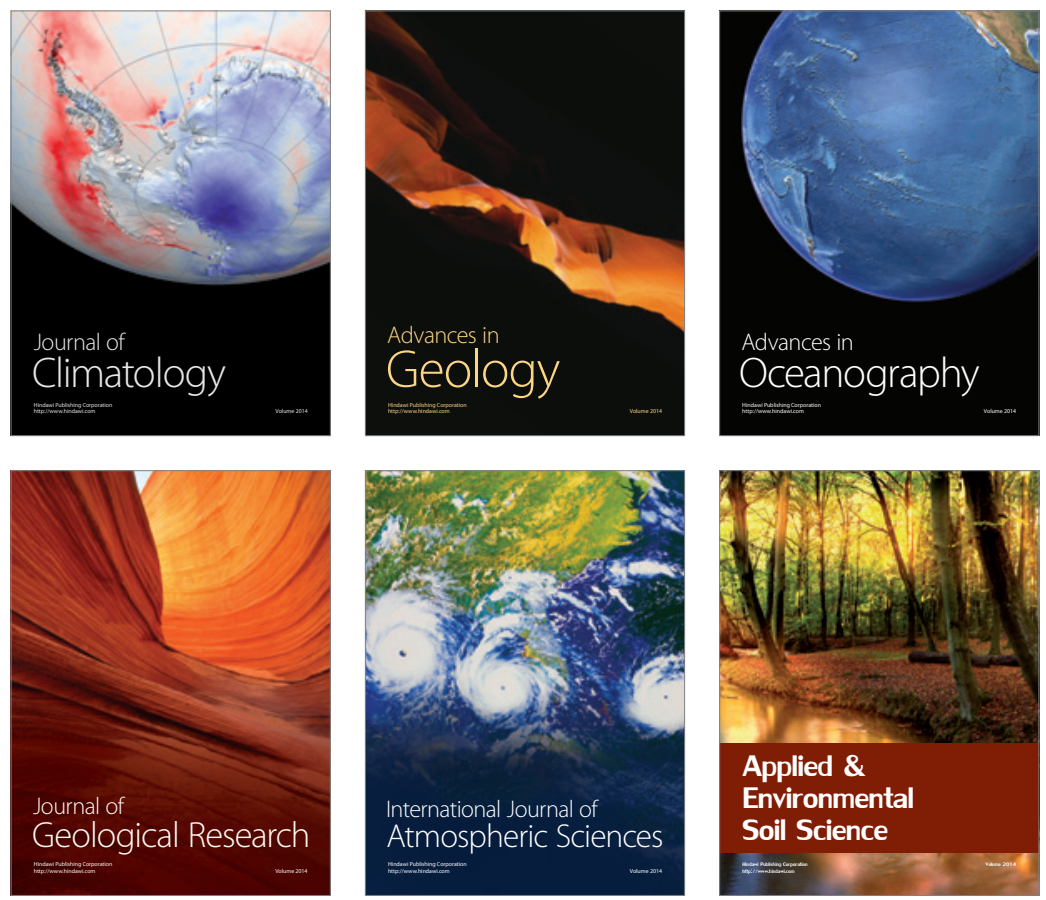
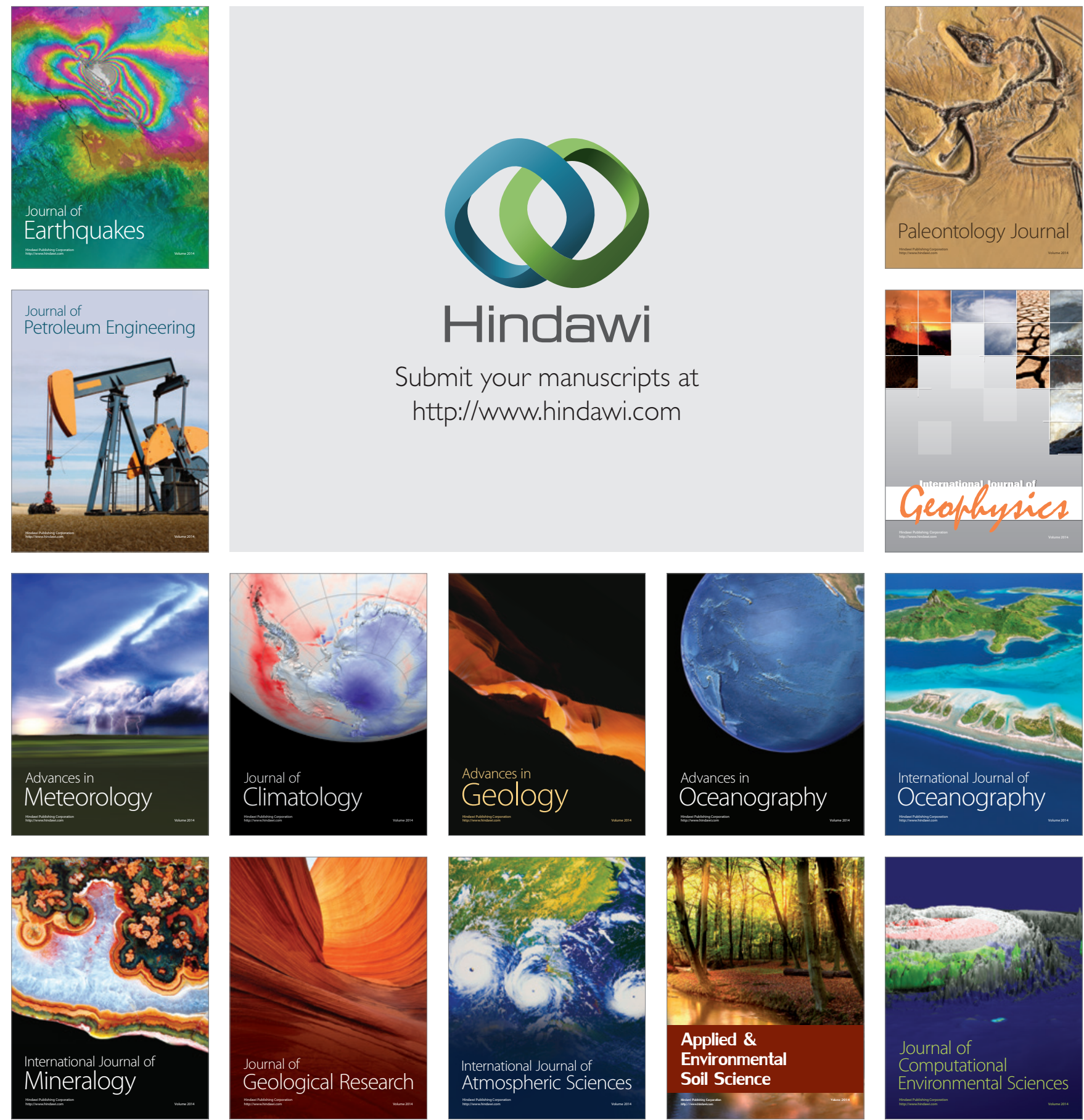